\title{
Diffuse vascular ectasia of the antrum, duodenum, and jejunum in a patient with nodular regenerative hyperplasia. Lack of response to portosystemic shunt or gastrectomy
}

\author{
P Calès, J-J Voigt, J-L Payen, E Bloom, P Berg, J-P Vinel, B Pradère, P Broussy, J-P Pascal
}

\begin{abstract}
The case is reported of a 70 year old man who presented with severe anaemia because of chronic gastrointestinal blood loss. This loss was ascribed to vascular ectasia resembling the gastric antral vascular ectasia syndrome but extended to include the antrum, the duodenum, the jejunum, and, possibly, the cardiac area. This condition was associated with portal hypertension as a result of nodular regenerative hyperplasia. Consecutive treatments including sucralfate, prostaglandin $\mathbf{E}_{2}$, propranolol, organic nitrates, pentoxyphilline, corticosteroids, endoscopic sclerotherapy, portosystemic shunt, total gastrectomy, proved ineffective.

(Gut 1993; 34: 558-561)
\end{abstract}

Gastric antral vascular ectasia is a rare cause of chronic gastrointestinal blood loss which was first described in 1953. ' Since then, more than 60 cases have been reported but many of them in recent years have been diagnosed incorrectly because this lesion has been misinterpreted. This lesion consists of multiple flat red spots, measuring 1 to $5 \mathrm{~mm}$ in size, which are found very close together, often aggregated into red linear stripes converging on the pylorus, which resembles the stripes of a watermelon..$^{23}$ Gastric antral vascular ectasia has often been seen in the elderly and in association with hepatic cirrhosis and achlorhydia. We report a case in association with nodular regenerative hyperplasia where vascular ectasia was found in the antrum, the duodenum, and the jejunum. The severity of the condition was shown by a severe blood loss which led to the use of different treatments such as propranolol, endoscopic sclerotherapy, portosystemic shunt, and total gastrectomy, none of which were successful.

\section{Case report}

A 70 year old white man was diagnosed as having a severe iron deficient anaemia in September 1988 (haemoglobin, $56 \mathrm{~g} / \mathrm{l}$; ferritin, $6 \mathrm{ng} / \mathrm{ml}$ (normal, $>20 \mathrm{ng} / \mathrm{ml}$ )). An upper gastrointestinal endoscopy examination showed 'antral purpura'. Barium tests and colonoscopy examination on the small bowel were normal. Coeliac and superior mesenteric angiography were also normal. Chromium tagged red cell studies showed gastrointestinal blood loss at a maximum rate of $204 \mathrm{ml} / \mathrm{d}$. He was treated at first with blood transfusions, oral iron, antacids, and antihistamine $_{2}$ receptors which was replaced, two months later, by enprostil (a prostaglandin $\mathrm{E}_{2}$ ). In January 1989, he was referred to a haematology unit with persistent anaemia. The results of a bonemarrow biopsy were compatible with an iron deficient anaemia. Abdominal computed tomography showed splenomegaly. A liver biopsy was performed because the alcaline phosphatase concentration was raised and nodular regenerative hyperplasia was diagnosed. There was no further disorder found with the nodular regenerative hyperplasia.

In addition to the blood transfusions and iron supplementation, he was treated with sucralfate, propranolol, organic nitrates, and pentoxyphillin during the following months. Anaemia persisted, however, and he was referred to our unit in July 1989. Examination showed him to be pale but other tests were normal. The serum vitamin B-12, folates, creatinine values were normal, as were coagulation tests. Gastric parietal cells, intrinsic factor, and other autoantibodies were absent. Pentagastrin tests showed achlorhydria. Serum hormone values were: gastrin, 100 and $116 \mathrm{pg} / \mathrm{ml}$ (normal upper limit, 100); serotonin, $377 \mathrm{ng} / \mathrm{ml}$ (normal upper limit, 470); glucagon, $28 \mathrm{fmol} / \mathrm{l}$ (normal upper limit, 48); 5-hydroxindole acetic acid, $6.44 \mathrm{mg} / \mathrm{d}$ (normal upper limit, 7). Upper gastrointestinal endoscopy showed diffuse, small (1 to $5 \mathrm{~mm}$ diameter) flat red cherry spots in the antrum (Fig 1) and in the duodenum. This pattern suggested gastric antral vascular ectasia. A similar pattern of red cherry spots was also seen in the cardiac area (Fig 2). Severe congestive gastropathy in the fundus and medium sized oesophageal varices were also seen. Antral and duodenal biopsies showed ectatic mucosal blood vessels (Fig 3).

The patient was discharged after a blood transfusion and given iron treatment. He presented with overt gastrointestinal blood loss in following months. Further upper gastrointestinal endoscopies showed oozing blood 
coming from the antrum or duodenum. We were able to see the progressive confluence of red spots into red stripes. Antrectomy was not attempted because the duodenum was affected by ectasia. We thought that portal hypertension could be a contributory factor to the ectasia and therefore a mesentericocaval shunt with a jugular graft was performed in October 1989. Portal venous blood pressure fell from 23 to $14 \mathrm{~mm} \mathrm{Hg}$ during surgery. The gross appearances of the stomach, duodenum and jejunum were normal but the surface of the liver seemed nodular. Liver biopsy examination confirmed nodular regenerative hyperplasia (Fig 4) and transmural antral biopsy examination showed gastric antral vascular ectasia with the ectasia of some superficial vessels occluded by fibrin thrombi and fibromuscular hyperplasia of lamina propria (Fig 5).

The patient was discharged and remained well during the following two months. He then presented with melaena (haemoglobin, $47 \mathrm{~g} / \mathrm{l}$ ) and mild hepatic encephalopathy. Upper gastrointestinal endoscopy examination indicated oozing blood from duodenal ectasia. The shunt patency was found by Doppler ultrasound. Treatment with endoscopic sclerotherapy was

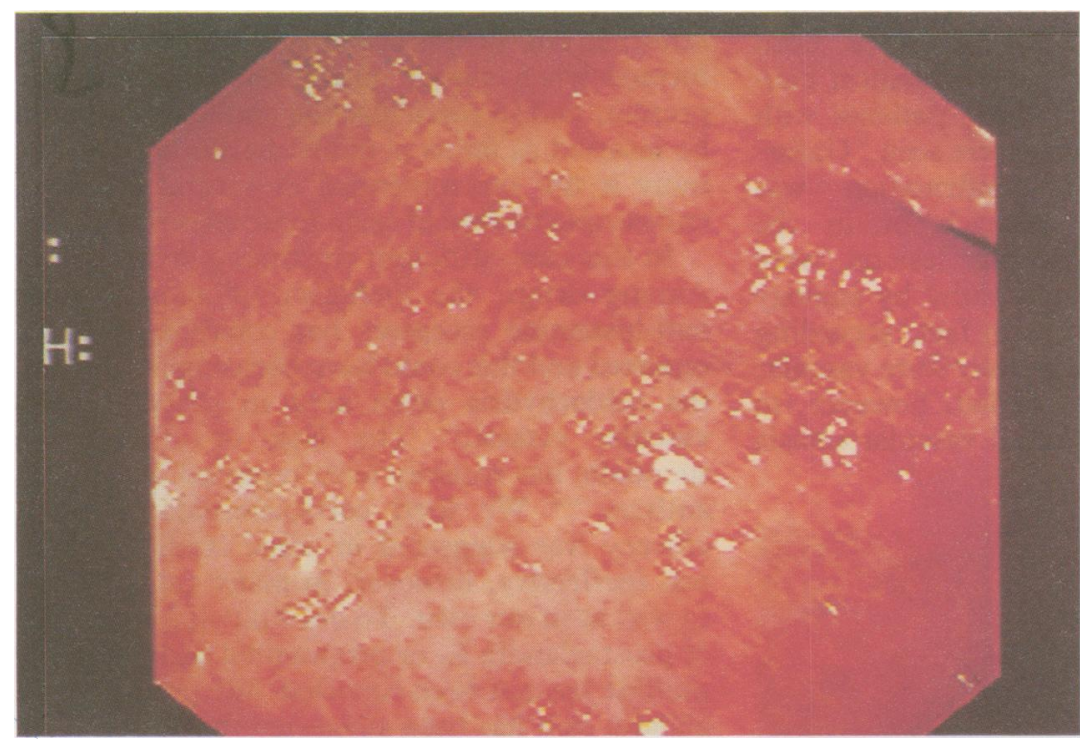

Figure 1: Multiple diffuse flat red spots in the antrum.

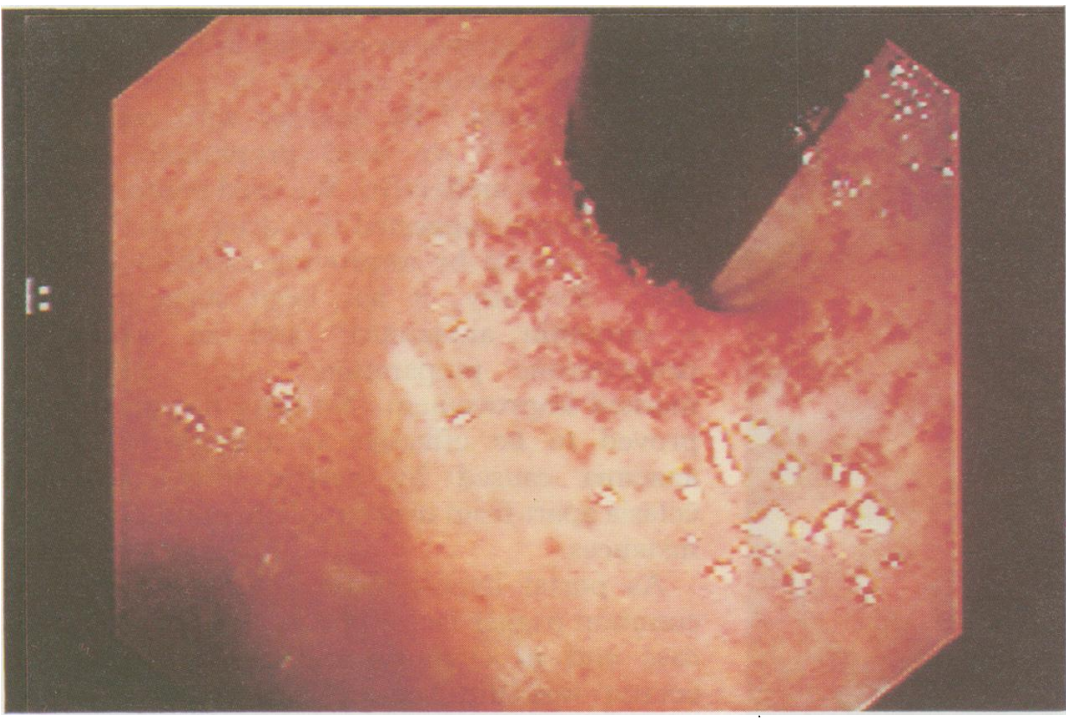

Figure 2: Several red spots are present around the cardia. given using polidocanol (concentration 1\%). This was repeated on seven occasions during the next two months. A total of $220 \mathrm{ml}$ were injected into the duodenum, $180 \mathrm{ml}$ into the antrum, and $12 \mathrm{ml}$ into the cardiac area. In January 1990, anaemia still persisted with gastrointestinal blood loss varying from 43 to $248 \mathrm{ml} / \mathrm{d}$. Upper gastrointestinal endoscopy examination showed the disappearance of red spots in the duodenum, and improved pattern in the antrum, and bleeding from severe congestive gastropathy in the fundus. Scanning showed the tagged red cell count to be normal and an attempt at jejunoscopy was unsuccessful.

The patient had a total gastrectomy with an omega intestinal loop anastomosis to keep the access clear to the duodenum. The patient was discharged and remained well for one month. He presented again with anaemia and blood loss of 94 to $278 \mathrm{ml} / \mathrm{d}$. Haematological tests were normal. Jejunoscopy showed diffuse red spots on the first four examined intestinal loops. Treatment with corticosteroids was not beneficial. Changes in the liver function test were mild and remained stable throughout follow up. The patient died in June 1990 of cachexia and hepatic encephalopathy. More than 120 blood units had been transfused during the course of the disease.

\section{Discussion}

New aspects of gastric antral vascular ectasia syndrome were seen in this case. About half of the previous cases were associated with cirrhosis, either alcoholic or post-hepatitic, and more recently with primary biliary cirrhosis. ${ }^{4}$ This is

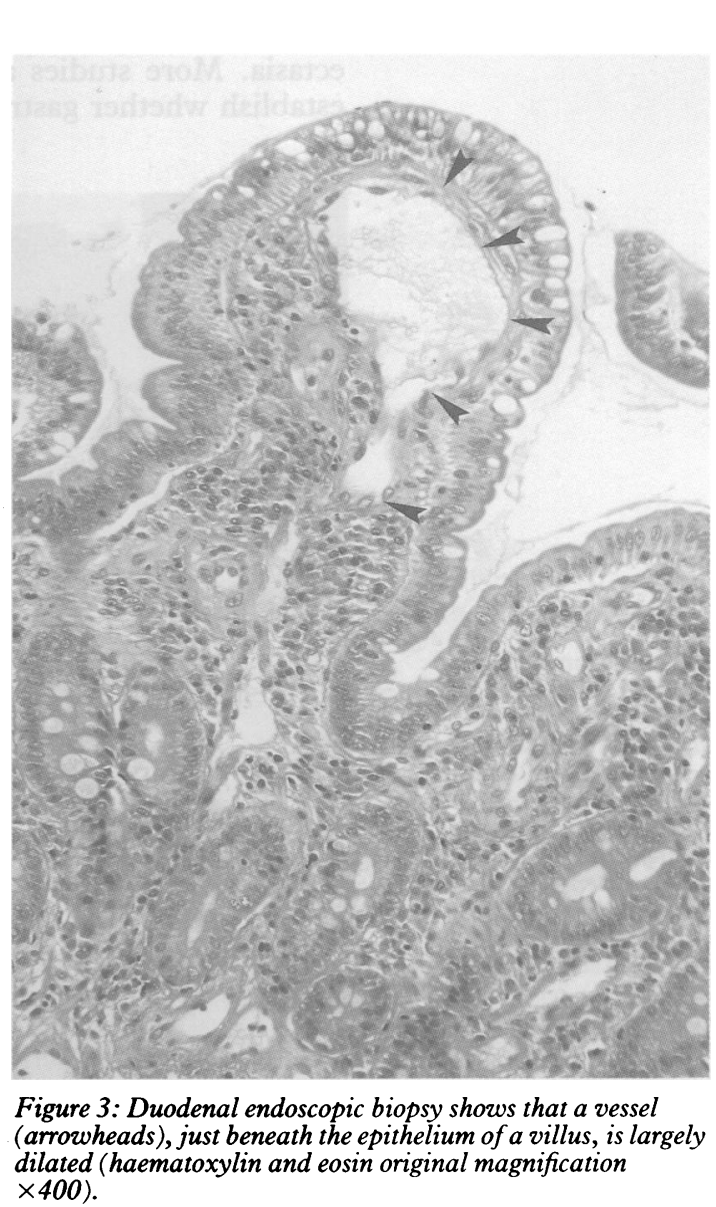




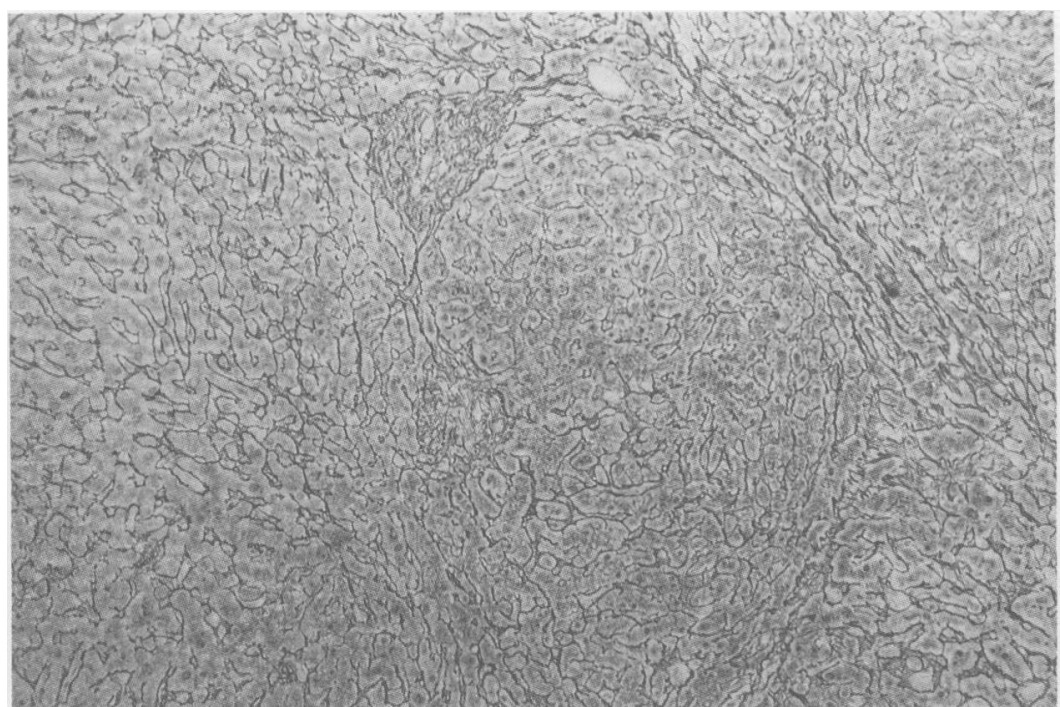

Figure 4: Surgical liver biopsy shows nodular regenerative hyperplasia. A nodule is outlined by condensation of the surrounding reticulin fibres (reticulin original magnification $\times 100)$.

the first report of a case associated with nodular regenerative hyperplasia.

By definition, gastric antral vascular ectasia are only present in the antrum. Some brief descriptions of ectopic ectasia have been reported, however, in the cardiac area, ${ }^{56}$ gastric corpus, ${ }^{2}$ duodenum, ${ }^{6-8}$ and perhaps in the colon. ${ }^{6}$ Most of these cases, however, have been reported in abstracts ${ }^{6}$ and no histological confirmation given. Recently, three patients with congestive gastroenteropathy were seen. ${ }^{9}$ Unfortunately, no histologic confirmation was obtained either in the stomach or in the duodenum. These endoscopic lesions were called congestive gastroenteropathy by analogy with congestive gastropathy. In fact, according to the photographs, we think they were vascular ectasia. More studies are needed, however, to establish whether gastric antral vascular ectasia

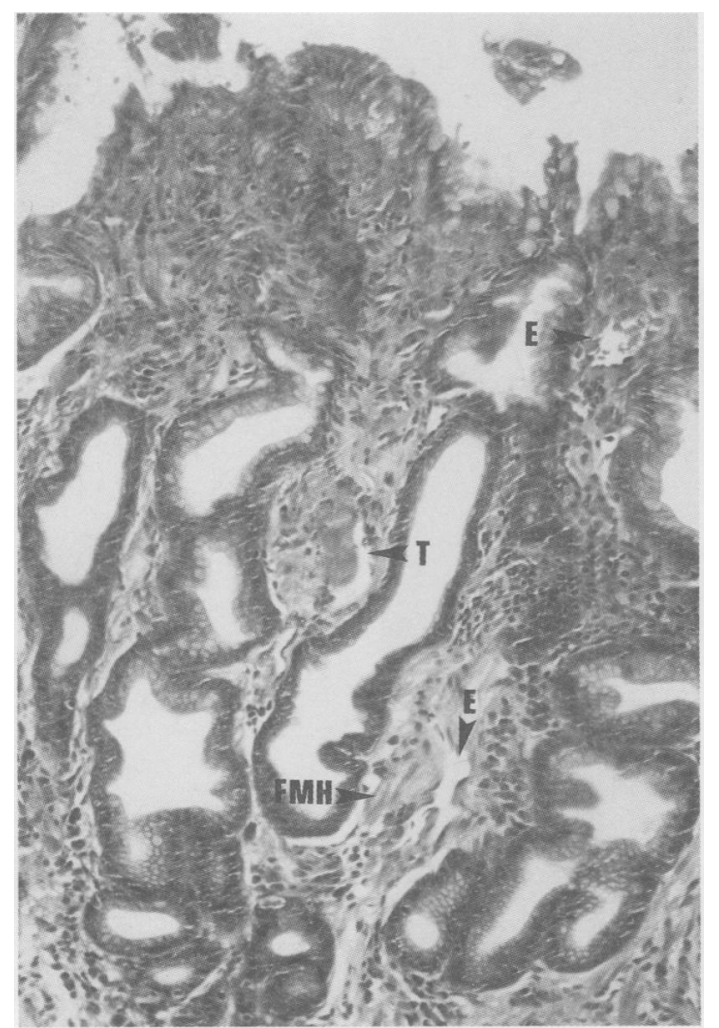

and severe congestive gastropathy are distinct entities or not.

In this case, ectasia were diffusely spread in the upper gastrointestinal tract. The classic endoscopic pattern of gastric antral vascular ectasia is watermelon stomach, ${ }^{4}$ but there is also the diffuse form ${ }^{1011}$ which we have found to be more usual. ${ }^{12}$ It is important to note that these were histologically confirmed in the antrum. In the duodenum, however, we only detected ectatic vessels. Biopsy examination was not performed in the cardiac area owing to the possible presence of submucosal varices. It must be emphasised, however, that these ectopic ectasia are probably rare or not clinically relevant. Indeed, in all the cases of gastric antral vascular ectasia where antrectomy was performed, anaemia disappeared on every occasion. By contrast, significant amounts of blood oozing from the duodenum was seen from the beginning in our patient, thus preventing us from performing antrectomy. Finally, total gastrectomy was not successful because of the amount of bleeding from the jejunum. Eventually, this patient died from the consequences of persistent severe bleeding from the jejunum.

The presence of ectopic lesions has several consequences. Firstly, complete upper gastrointestinal endoscopic examination should be performed when gastric antral vascular ectasia is present. and in particular the endoscope should be inserted as far as possible. Secondly, antrectomy is not recommended as several types of endoscopic treatment seem more effective. ${ }^{13-15}$

In this case, different treatments were given. Among drugs, the inefficacy of antacids and anti-histamine receptors has consistently been reported and this could have been expected from the achlorhydria often seen in gastric antral vascular ectasia. ${ }^{35}$ The lack of efficacy of sucrafalte has recently been reported by several authors. ${ }^{14-16}$ We used corticosteroids as their efficacy was suggested in some studies..$^{31017} \mathrm{It}$ was ineffective, however, in many studies ${ }^{811} 1418$ as well as in our own. To our knowledge the use of prostaglandin $\mathrm{E}_{2}$ or propranolol and pentoxyphilline has not been reported. We used prostaglandin as it has been suggested that a defect in prostaglandin $\mathrm{E}_{2}$ content in gastric mucosa has been found in patients with cirrhosis. ${ }^{19}$ Further studies have shown an increase in prostaglandin $\mathrm{E}_{2}$ gastric mucosal content in gastric antral vascular ectasia. ${ }^{20} \mathrm{By}$ analogy with congestive gastropathy, ${ }^{2122}$ we used propranolol but it proved to be ineffective. We used pentoxifylline as it has been suggested this drug could protect gastric mucosa by improving capillary circulation. ${ }^{23}$ Recently, it has been suggested that a serotonin antagonist ${ }^{24}$ and an oestrogenprogesterone preparation ${ }^{25}$ could achieve a marked improvement. No drug has up to now proved to be effective in the correction of anaemia caused by gastric antral vascular ectasia apart from iron supplementation in some instances.

As portal hypertension could have been a common trigger factor of vascular ectasia in this case and in cirrhosis and as the spread of ectasia was diffuse, we performed a portosystemic shunt. It was unsuccessful and it also 
seemed to aggravate the process of ectasia. In 1975, Testard et al reported the same lack of efficacy of portocaval anastomosis in a case of gastric antral vascular ectasia. ${ }^{26}$ These findings, however, cannot entirely rule out the part played by portal hypertension. Some authors argue that gastric antral vascular ectasia could be a result of vasoactive components, such as gastrin, ${ }^{2}$ 5 hydroxytryptamine, and vasoactive intestinal polypeptide..$^{27}$ This could explain the occurrence of gastric antral vascular ectasia not only in cirrhosis, where increases in such hormones have been seen, but also in other conditions where hypergastrinaemia was reported. It should be noted that portocaval anastomosis might increase such substances ${ }^{28}$ and, as a result, favour the development of vascular ectasia. A logical approach to the treatment of gastric antral vascular ectasia in portal hypertension would be to lower the level of portosystemic shunting and not the level of portal hypertension in itself. In the light of these findings and as a result of our experience, it seems that portocaval shunt should not be attempted in gastric antral vascular ectasia. The role of hypergastrinaemia should be reappraised as intestinal ectasia continued to aggravate after total gastrectomy in our case and new ectopic vascular ectasia were seen after partial gastrectomy in another case.

We attempted to treat vascular ectasia by endoscopic sclerotherapy. Some improvement was subsequently seen on endoscopic examination both in the duodenum and in the antrum. The efficacy of this type of treatment has already been suggested. ${ }^{829}$ Although there was improvement, it seems to us that the fundic mucosa deteriorated after this treatment. This side effect has been seen by Petrini et al with the occurrence of bleeding from fundic congestive gastropathy after treatment of gastric antral vascular ectasia by heat probe. ${ }^{12}$ Other groups have reported better results in gastric antral vascular ectasia using laser ${ }^{1314}$ or heat probe. ${ }^{15}$

In conclusion, this case of vascular ectasia was characterised by unusual patterns: association with nodular regenerative hyperplasia; diffuse location of red spots in the antrum; duodenum, and jejunum; lack of efficacy of endoscopic sclerotherapy and surgical approaches. We should not forget, however, that vascular ectasia are generally found in the antrum and that local treatments seem highly effective.

1 Rider JA, Klotz A, Kirsner JB. Gastritis with veno-capillary ectasia as a source of massive gastric hemorrhage. Gastroectasia as a source of massive
enterology $1953 ; 24: 118-23$.

2 Quintero E, Piqué JM, Bombi JA, Bordas JM, Sentis J, Elen $\mathrm{M}$, et al. Gastric mucosal vascular ectasias causing bleedin in cirrhosis. A distinct entity associated with hypergastri- nemia and low serum levels of pepsinogen I. Gastroenterology 1987; 93: 1054-61.

3 Jabbari M, Cherry R, Lough JO, Daly DS, Kinnear DG Goresky CA. Gastric antral vascular ectasia: the watermelon stomach. Gastroenterology 1984; 87: 1165-70.

4 Koivisto PVI. Gastric antral vascular ectasia and primary biliary cirrhosis. Endoscopy 1988; 20: 334

5 Borsch G, Schafer K, Schmidt G, Menne R, Tiedjen KU. Ectasie vasculaire antrale diffuse: cause rare d'hémorragie gastrointestinale sévère. Acta Endosc 1985; 15: 239-43.

6 Lux G, Fruhmorgen P, Rosch W. Diffuse telangiectasia of the upper GI-tract. [Abstract]. Endoscopy 1979; 11: 281 .

7 Wheeler MH, Smith PM, Cotton PB, Evans DMD, Lawrie $\mathrm{BM}$. Abnormal blood vessels in the gastric antrum. A cause of upper-gastrointestinal bleeding. Dig Dis Sci 1979; 2: of upper-

8 Rose JDR. Endoscopic injection of alcohol for bleeding from gastroduodenal vascular anomalies. BMF 1987; 295:93-4. Thiruvengadam R, Gostout CJ. Congestive gastroenteropathy - an extension of nonvariceal upper gastrointestinal bleeding in portal hypertension. Gastrointest Endosc 1989; 6: 504-7.

10 Kruger R, Ryan ME, Dickson KB, Nunez JF. Diffus vascular ectasia of the gastric antrum. Am $\mathcal{F}$ Gastroentero 1987; 5: 421-6

11 Lee FL, Costello F, Flanagan N, Vasudev KS. Diffuse antra vascular ectasia. Gastrointest Endosc 1984; 2: 87-90.

12 Calès $\mathrm{P}$, Payen JL, Berg P, Voigt JJ, Desmorat $\mathrm{H}$, Vinel JP, $e$ al. Antral vasvular ectasia, new endoscopic and clinical spectrum. Gastroenterology 1991; 100: A38.

13 Frager JD, Brandt LJ, Frank MS, Morecki R. Treatment of patient with watermelon stomach using transendoscopic patient with watermelon stomach using transendoscopic

14 Gostout CI, Ahlquist DA, Radford CM, Viggiano TR, Bowye BA, Balm RK. Endoscopic laser therapy for watermelon BA, Balm RK. Endoscopic laser therapy
stomach. Gastroenterology 1989; 96: 1462-5.

15 Petrini JL, Johnston JH. Heat probe treatment for antral vascular ectasia. Gastrointest Endosc 1989; 4: 324-8.

16 Jouanolle H, Bretagne JF, Ramee MP, Lancien G, Le JeanColin I, Heresbach D, et al. Ectasie vasculaire antrale et sclérodermie. Aspects endoscopiques, radiologiques et anatomopathologiques d'une association originale. Gastroenterol Clin Biol 1989; 13: 217-21.

17 Calam J, Walker RJ. Antral vascular lesion, achlorhydria, and chronic gastrointestinal blood loss. Response to steroids. Dig Dis Sci 1980; 3: 236-9.

8 Rawlinson WD, Barr GD, Lin BPC. Antral vascular ectasia. The 'watermelon' stomach. Med $\mathcal{7}$ Aust 1986; 144: 709-11.

19 Arawaka T, Satoh H, Fukuda T, Nakamura H, Kobayashi K. Endogenous prostaglandin E2 in gastric mucosa of patients with alcoholic cirrhosis and portal hypertension. Gastroenterology 1987; 93: 135-40.

20 Saperas E, Ayuso RMP, Poca E, Bordas JM, Gaya J, Piqué JM. Increased gastric PGE2 biosynthesis in cirrhotic patients with gastric vascular ectasia. Am f Gastroentero 1990; 85: 138-44.

21 Hosking SW, Kennedy HJ, Seddon I, Triger DR. The role of propranolol in congestive gastropathy of portal hypertension. Hepatology 1987; 7: 437-41.

22 Perez-Ayuso RM, Piqué JM, Bosch J, Panés J, Gonzalez A, Pérez $\mathrm{R}$, et al. Propranolol in prevention of recurrent bleeding from severe portal hypertensive gastropathy in cirrhosis. A multicentre randomized controlled trial. Lancet 1991; 337: 1431-4.

23 Tominaga G, Waxman K, Soliman H, Sarfeh J, Bui HX, Tarnawski A. Protective effect of pentoxifylline on gastric Tarnawski A. Protective effect of pe

24 Pina Cabral JE, Pontes JM, Toste M, Camacho E, Correi Leitao, Freitas D, et al. Watermelon stomach: treatmen with a serotonin antagonist. Am $\mathcal{F}$ Gastroenterol 1991; 86: 927-8

25 Moss SF, Ghosh P, Thomas DM, Jackson JE, Calam J. Gastric antral vascular ectasia: maintenance treatment with oestrogen-progesterone. Gut 1992; 33: 715-7.

26 Testart J, Hemet J, Metayer P. Gastrite hémorragique par coagulation intra-vasculaire localisée au cours de l'évolution d'une 'cirrhose inflammatoire cryptogénétique'. Sem Hop Paris 1975; 51: 1235-41.

27 Lowes JR, Rode J. Neuroendocrine cell proliferations in gastric antral vascular ectasia. Gastroenterology 1989; 97 $207-12$.

28 Hunt S, Vaamonde CA, Rattassi T, Berian MG, Said SI, Papper S. Circulating levels of vasoactive intestinal polypeptide in liver disease. Arch Intern Med 1979; 139: 994-6.

29 Colin-Jones DG. Upper gastrointestinal lesions. In: Salmon $\mathrm{PR}$, ed. Advances in diagnosis and therapy. Gastrointestinal endoscopy, vol 1. London: Chapman \& Hall Medical, 1984 92. 